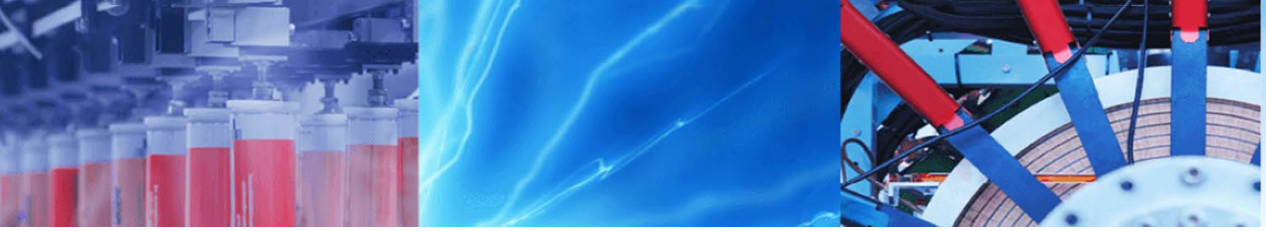

Research Article

\title{
Unique thiophilic affinity MOFs as specific sorbent for disulfide bond-containing compounds capture
}

\author{
Qijuan Wen ${ }^{1} \cdot$ Tanghao Sun $^{1} \cdot$ Qi Wang $^{1} \cdot$ Wenwen Huang $^{2} \cdot$ Yunchun Liu $^{1}$
}

(c) Springer Nature Switzerland AG 2019

\begin{abstract}
Stationary sorbents play a key role in the separation process. We present here a kind of unique separative material, called thiophilic affinity MOFs, as specific sorbent for the capture of compounds containing disulfide-bond. The sorbent was obtained through epoxide ring-opening reaction among MOF-5- $\mathrm{NH}_{2}$, $\operatorname{tris}(2,3$-epoxypropyl) isocyanurate, and thiophilic reagents under mild reaction condition. The synthesized sorbent was characterized with X-ray diffraction, scanning electron microscope, transmission electron microscope, Fourier transform infrared, thermogravimetric analysis and $\mathrm{N}_{2}$ absorption. The capillary electrophoresis experiments verified their high specific recognization and separation for disulfide bond-containing compounds.
\end{abstract}

Keywords MOFs - Thiophilic affinity sorbent · Specific recognization and separation · Disulfide bond-containing compounds

\section{Introduction}

Metal organic frameworks (MOFs) were generated by the polymerization reaction of organic linker and inorganic metal clusters to form 3D porous materials [1, 2]. Compared with other inorganic porous materials, MOFs have some unique characteristics, which make them have great potential for the separation. Firstly, fascinating surface areas can meet the requirement for normal stationary sorbents perfectly. Secondly, good thermal stability make it can be used in severe experiment condition; Thirdly multifarious organic linker make it have different functional surface. [3-8]. However, the exploration of MOFs as efficient sorbents for the separation of liquid sample are relatively lagged behind. There are two main reasons: (1) some MOFs will lose its stability in polar solvent so that they only can use a single nonpolar or low polar solvent [9]; (2) specific liquid separation beyond the adsorption-based mechanism is a challenge for long time [10,11]. Therefore, it is urgent and imperative to develop a stable and effective MOFs based materials for the specific liquid separation.

The superamolecular metallopolymer and polymerMOF hybrid materials was proposed by Cohen et al. [12, 13] Supermaolecular metallopolymer can formed 'soft' organic building block connecting by metal ions, when the organic polymer linker and metal ions is changed, and their physicochemical properties would change, too. The polymer-MOF hybrid materials integrate organic polymer into the MOF lattice because the polymers have necessary mulitopic ligands for MOF formation. It can exhibit properties of MOFs such as high porosity and crystallinty, as well as polymer properties such as high stability. The integrated properties of hybrid materials will expand application of MOF [14-18].

It is well-known that sulfone is attractive as affinity ligand for many applications, such as probe, self-assembly and separation [19]. Sulfone can covalently react with disulfide bond to form esters in high concentration salt

$\triangle$ Yunchun Liu, wblych@ahnu.edu.cn | ${ }^{1}$ Key Laboratory of Functional Molecular Solids, Ministry of Education, College of Chemistry and Materials Science, Anhui Normal University, Wuhu 241000, China. ${ }^{2}$ Beijing Center for Physical and Chemical Analysis, Beijing Key Laboratory of Detection Technology and Quality Evaluation of Organic Material, Beijing 100094, China.

SN Applied Sciences (2019) 1:747 | https://doi.org/10.1007/s42452-019-0799-3

Received: 11 March 2019 / Accepted: 11 June 2019 / Published online: 19 June 2019 
solution and dissociate in low concentration. This association between thiophilic sorbents and disulfide bondcontaining compounds was discovered firstly by Porath et al. [20], and the thiophilic affinity chromatogrphy (TAC) method was found. Nowadays, extensive attention have been paid to thiophlic affinity adsorbents. Thamarapu et al. used thiophilic interaction chromatography to separate transferrins in serum, which may provide a sample and efficient method to monitor levels of transferrins for monitoring the progress of Alzheimer's disease [21]. What's more, Elzbie displayed a thiophilic interaction (3S, T-gel) chromatography methodology to isolate various PSA molecular forms present in biological fluids [22]. High quality separation material should be charaterized by high stength and easy surface modification. However, the most existing thiophlic chrmatographic materials are based on soft substrate such as gel [23] or fiber [24]. They have poor mechanical strength and difficult to storage.

The MOFs materials synthesized by polymerization have high mechanical strength and high stability. In this article, a novel unique thiophilic affinity MOFs were designed and synthesized based on copolymerization reaction among the MOF-5- $\mathrm{NH}_{2}$ derivatives, tris(2,3-epoxypropyl) isocyanurate (TEPIC) and sulfamide (SFA). The MOF-5- $\mathrm{NH}_{2}$ can assemble with TEPIC and SFA spontaneously in solution. The prepared polymer-MOF hybrid thiophilic affinity material were competent to specifically recognize and enrich the disulfide bond-containing compounds.

\section{Experimental section}

\subsection{Materials}

The thiophilic regents sulfamide (SFA) was purchased from Aladdin and its chemical structure were shown in Fig. 1. $\mathrm{Zn}\left(\mathrm{NO}_{3}\right)_{2} \cdot 6 \mathrm{H}_{2} \mathrm{O}$, and tris(2,3-epoxypropyl) isocyanurate (TEPIC) also were purchased from Aladdin (Shanghai, China). 2-aminoterephthalic acid was purchased from Ark Pharm (Shanghai, China). N,N-dimethylformamide (DMF), dimethyl sulfoxide (DMSO), acetonitrile (ACN), methanol and ethanol were obtained from Sinopharm Chemical Reagent (Shanghai, China). Bis(4-hydroxyphenyl) disulfide $(2 \mathrm{~S}-\mathrm{OH})$ and $4,4^{\prime}$-(dihydroxyphenyl) methane $(2-\mathrm{OH})$ were purchased separately from TCl (Shanghai, China) and Aladdin (Shanghai, China).

All chemicals and reagents were at least of analytical grade. Ultrapure water $(18.2 \mathrm{M} \Omega \mathrm{cm})$ was obtained from a water purification system (PSDK2-10-C, Beijing city, China).

Standard solution of bis(4-hydroxyphenyl) disulfide (2S-OH) $\left(0.1 \mathrm{mg} \mathrm{mL}^{-1}\right)$ and bis 4, 4'-Dihydroxydiphenyl methane $(2-\mathrm{OH})\left(0.1 \mathrm{mg} \mathrm{mL}^{-1}\right)$ were prepared with acetonitrile. The loading buffer $(\mathrm{pH}=6.2)$ was composed of $\mathrm{KCl}$

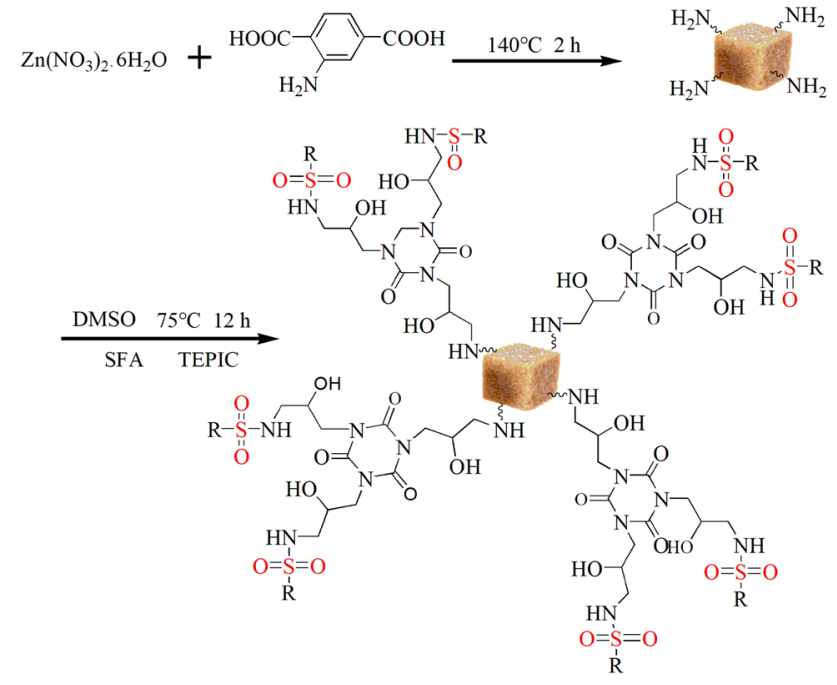

Fig. 1 Preparation process of MOF-5-NH $\mathrm{N}_{2} @ \mathrm{P}(\mathrm{TEPIC}-\mathrm{CO}-\mathrm{SFA})$

(3.727 $\left.\mathrm{g}, 0.50 \mathrm{~mol} \mathrm{~L}^{-1}\right)$ and $\mathrm{Na}_{2} \mathrm{HPO}_{4}\left(1.433 \mathrm{~g}, 0.04 \mathrm{~mol} \mathrm{~L}^{-1}\right)$, with ultrapure water dissolved and transferred into $100 \mathrm{~mL}$ volumetric flask. The preparation of eluent $(\mathrm{pH}=6.2)$ with $\mathrm{Na}_{2} \mathrm{HPO}_{4}\left(1.433 \mathrm{~g}, 0.04 \mathrm{~mol} \mathrm{~L}^{-1}\right)$ was same as above. The two kinds of solution were used for immobilized and elution of sample. The background buffer solution was prepared with $\mathrm{Na}_{2} \mathrm{HPO}_{4}\left(0.895 \mathrm{~g}, 0.05 \mathrm{~mol} \mathrm{~L}^{-1}, \mathrm{pH}=8.5\right)$. All of the above buffer solution were prepared with sodium citrate regulating $\mathrm{pH}$ to designated value and were reserved in refrigerator for $\mathrm{CE}$.

\subsection{Preparation of thiophilic affinity MOFs}

The matrix MOF-5- $\mathrm{NH}_{2}$ was prepared by the method of literature and partly improved [25]: $\mathrm{Zn}\left(\mathrm{NO}_{3}\right)_{2} \cdot 6 \mathrm{H}_{2} \mathrm{O}(0.595 \mathrm{~g}$, $2.0 \mathrm{mmol}$ ) were dispersed in $50 \mathrm{~mL} \mathrm{DMF}$ in a three-necked flask. Subsequently, 2-amino terephthalic acid $(0.181 \mathrm{~g}$, $1.0 \mathrm{mmol}$ ) was added into the above mixed solution and the polymerization was kept for $2 \mathrm{~h}$ under stirring at $140{ }^{\circ} \mathrm{C}$. Then, the solid precipitates were collected and washed thoroughly with DMF, ethanol for three times, respectively. When the unreacted substance was removed, the prepared MOF- $5-\mathrm{NH}_{2}$ was dried at $50^{\circ} \mathrm{C}$ in the drying oven for $12 \mathrm{~h}$.

Afterwards, the above MOF-5-NH $(0.310 \mathrm{~g}, 0.4 \mathrm{mmol})$ as matrix, TEPIC $(0.119 \mathrm{~g}, 0.4 \mathrm{mmol})$ as the crosslinker, SFA $(0.038 \mathrm{~g}, 0.4 \mathrm{mmol})$ as functional monomer were wellblended in the $50 \mathrm{~mL}$ DMSO. Then the system was kept stirring for $12 \mathrm{~h}$ at $75^{\circ} \mathrm{C}$. The MOF-5-NH $\mathrm{NH}_{2} @ \mathrm{P}$ (TEPIC-Co-SFA) was synthesized based on the ring opening reaction of expoxy group. At last, the resulting sorbent was collected, followed by rinsed with methanol for three times before drying at $50^{\circ} \mathrm{C}$ overnight for future use. An illustration of 
the preparation of MOF-5-NH $\mathrm{NH}_{2} @ \mathrm{P}(\mathrm{TEPIC}-\mathrm{Co}-\mathrm{SFA})$ was presented in Fig. 1.

\subsection{Characterization}

Scanning electron microscopy (SEM, Hitachi S-4800, Japan) was performed at $5 \mathrm{kV}$. Transmission electron microscopy (TEM, Hitachi HT-7700, Japan) was performed at $100 \mathrm{kV}$. The X-ray diffraction (XRD, Bruker D8 Advance, German) patterns were recorded using $\mathrm{Cu} / \mathrm{Ka}$ radiation at $40 \mathrm{kV}$ and $40 \mathrm{~mA}$. Fourier transform infrared spectrometer (FTIR-21, Shimadzu, Japan) spectra were recorded from 4000 to $50 \mathrm{~cm}^{-1}$. Thermogravimetric analyses (TGA, DTG-60A, Japan) was performed under air atmosphere. The heating rate was $10^{\circ} \mathrm{C} \mathrm{min}^{-1}$ and the hold temperature was set to $800^{\circ} \mathrm{C}$. The specific surface area and porous behavior (BET, JW-BK112 JWGB SCI\&TECH, China) were measured by $\mathrm{N}_{2}$ adsorption and desorption at $77 \mathrm{~K}$. The sample detection was carried out by capillary electrophoresis (CE) apparatus (P/ACE ${ }^{\mathrm{TM}} \mathrm{MDQ}$, Beckman, USA).

\section{Results and discussion}

\subsection{Characterization}

\subsubsection{SEM and TEM of MOF-5-NH $\mathrm{NH}_{2} @ P(T E P I C-C O-S F A)$}

MOF-5 is an important archetype metal-organic framework which oxocentered $Z_{4}$ tetrahedra are connected with linear organodicarboxylates to produce a cubic network structure [26-28]. Due to its high specific area surface and controlled pore size, it has been studied in the separation technology [29]. But its organic unit are mainly composed of nonpolar functional group, according to the literature [29]. Some MOFs may degrade in the polar solvent, such as $\mathrm{H}_{2} \mathrm{O}$ and $\mathrm{CH}_{3} \mathrm{CN}, \mathrm{CH}_{3} \mathrm{OH}$. Therefore, the hydrophilic amino $\left(-\mathrm{NH}_{2}\right)$ group was tentatively introduced into MOF5. In this paper, we chose MOF-5-NH 2 , TEPIC and SFA as matrix, crosslinker, and functional monomers, respectively. The sulfone group was modified on the MOF through the epoxy ring opening reaction, and a polymer-MOF hybrids MOF-5-NH $\mathrm{NH}_{2} @$ P(TEPIC-co-SFA) was obtained, and it was severed as the affinity thiophilic sorbentin in the separated experiments.

The reaction temperature was found to be a key factor for the preparation of the affinity thiophilic sorbents. When the temperature was lower than $75^{\circ} \mathrm{C}$, the thiophilic affinity sorbent MOF-5-NH ${ }_{2} @ P$ (TEPIC-co-SFA) was not well formed; when the temperature was higher than $75^{\circ} \mathrm{C}$, the porous of the thiophilic affinity sorbent become dense, and even disappeared (Fig. 2), which would affect its separation ability. The reaction time was also crucial to synthesize the sorbent. No matter the time was above $12 \mathrm{~h}$ or below the $12 \mathrm{~h}$, the morphology of the sorbent was not intact (Fig. 3). Based on the above results, the optimal reaction condition was kept at $75^{\circ} \mathrm{C}$ for $12 \mathrm{~h}$. The obtained product was brown powder. The sorbent is nearly cubic with well-controlled skeletal and well distributed porous. TEM images (Fig. 4) further proved the sorbent is dispersed uniformly.

\subsubsection{XRD, FT-IR measurements}

The XRD patterns of MOF-5-NH $\mathrm{N}_{2}$ and MOF-5-NH $\mathrm{N}_{2} @ \mathrm{P}$ (TEPICCo-SFA) were shown in Fig. 5. MOFs-5- $\mathrm{NH}_{2}$ exhibited well-defined diffraction peaks. The diffraction peaks at $2 \theta=7.76^{\circ}(200), 9.74^{\circ}(220), 13.94^{\circ}(400)$ were attributed to the characteristic reflection of MOF-5- $\mathrm{NH}_{2}$ which were in accordance with the results in the literature [30]. However, the intensity of the synthesized MOF-5-NH $\mathrm{N}_{2} @$ P(TEPIC-coSFA) decreased apparently, which was attributed to the distortion of the MOF-5-NH $\mathrm{NH}_{2}$ crystal structure after combination with TEPIC-Co-SFA.

Fourier transform infrared (FT-IR) spectroscopy was used to detect the homologous infrared absorption characteristic peaks of the sorbent. As we can see from Fig. $6 \mathrm{a}, \mathrm{MOF}-5-\mathrm{NH}_{2}$ has two apparent stretching vibration at $3286 \mathrm{~cm}^{-1}$ and $3155 \mathrm{~cm}^{-1}$, which approved the vibration of $\mathrm{N}-\mathrm{H}$, but they were disappeared in MOF-5$\mathrm{NH}_{2} @ \mathrm{P}$ (TEPIC-Co-SFA) (Fig. 6c). It means that the amido of MOF-5- $\mathrm{NH}_{2}$ has coordinated with epoxy group. Due to the polymerization between SFA (Fig. 6b) and TEPIC, the characteristic stretching vibration of $-\mathrm{S}=\mathrm{O}$ of SFA slight blue shift from $1350 \mathrm{~cm}^{-1}$ and $1156 \mathrm{~cm}^{-1}$ to $1309 \mathrm{~cm}^{-1}$ and $1219 \mathrm{~cm}^{-1}$, which is consistent with the literature [31]. Peaks at 1600,1500 and $1390 \mathrm{~cm}^{-1}$ was related with the $\mathrm{C}=\mathrm{O}$ symmetric and asymmetric vibration in the carboxyl group (R-COO-) of the secondary unit $\left(\mathrm{Zn}_{4} \mathrm{O}_{6}{ }^{+}\right)$, which was from 2-amino terephthalic acid. Absorptive peaks of aromatic skeletal stretching vibration were at 1500 and $1600 \mathrm{~cm}^{-1}$. All these results confirm the presence of sulfone group in the sorbent.

\subsubsection{TGA, BET measurements}

The thermal stability of affinity thiophilic sorbent was characterized by the thermalgravimmetric analysis (TGA) in air atmosphere. As we can see from Fig. 7, the weight loss of MOF-5-NH $\mathrm{NH}_{2} @$ P(TEPIC-Co-SFA) is a three-steps process. A weight loss of about $12 \%$ was observed before $125^{\circ} \mathrm{C}$, which could be owing to the residual solvent molecule in the porous structure. The moisture in the surface and channels with weight loss of only $5 \%$ is observed between 125 and $310^{\circ} \mathrm{C}$. The decomposition of MOF-5$\mathrm{NH}_{2} @ \mathrm{P}$ (TEPIC-co-SFA) is detected at about $310^{\circ} \mathrm{C}$, which 

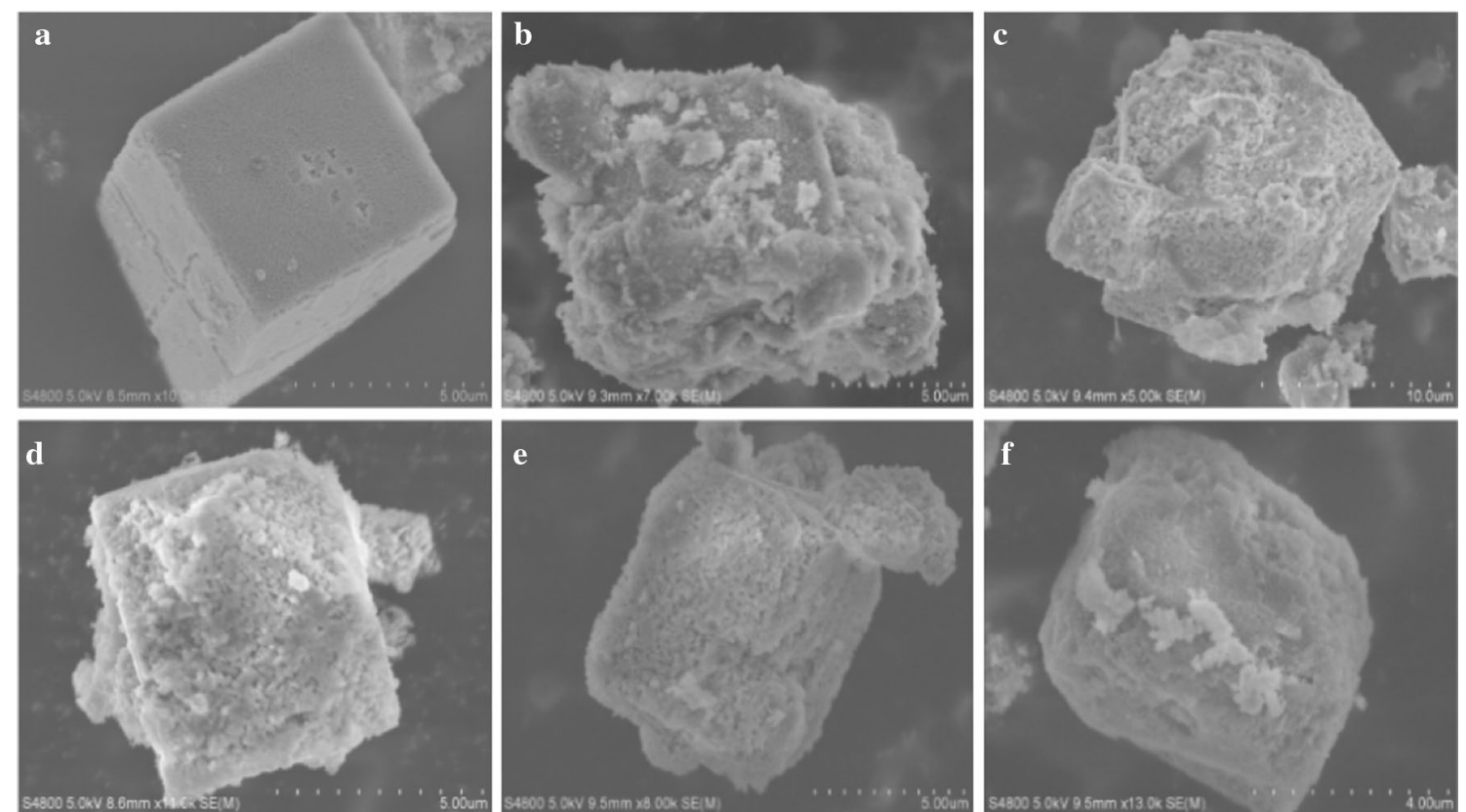

Fig. 2 SEM images of a MOF-5-NH ${ }_{2}$ and MOF-5-NH $\mathrm{N}_{2} @ \mathrm{P}(\mathrm{TEPIC}-\mathrm{CO}-\mathrm{SFA})$ at different reaction temperature b $55^{\circ} \mathrm{C}, \mathbf{c} 65^{\circ} \mathrm{C}, \mathbf{d} 75^{\circ} \mathrm{C}, \mathbf{e} 85^{\circ} \mathrm{C}, \mathbf{f}$ $95^{\circ} \mathrm{C}$
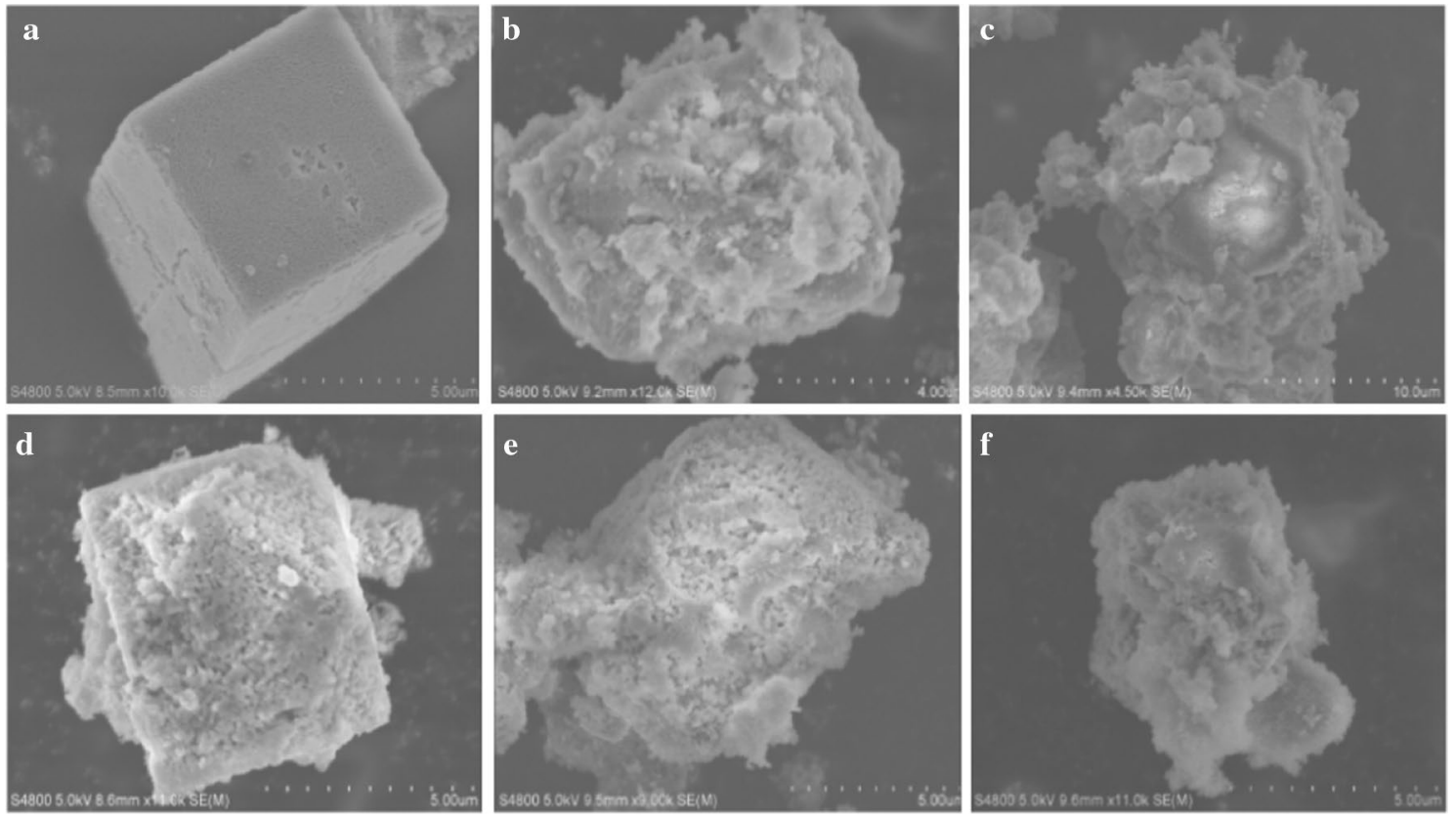

Fig. 3 SEM images of a MOF-5-NH ${ }_{2}$ and MOF-5-NH $\mathrm{NH}_{2} @ P(T E P I C-C O-S F A)$ for different reaction time b $8 \mathrm{~h}, \mathbf{c} 10 \mathrm{~h}, \mathbf{d} 12 \mathrm{~h}, \mathbf{e} 14 \mathrm{~h}$, f $16 \mathrm{~h}$

indicates that the obtained sample has excellent thermal stability. The major weight loss of MOF-5-NH $\mathrm{N}_{2} @ \mathrm{P}$ (TEPICco-SFA) sample is detected between 310 and $525^{\circ} \mathrm{C}$. The skeleton of MOF-5-NH ${ }_{2} @ P(T E P I C-C O-S F A)$ is destroyed completely when the temperature reach at $525^{\circ} \mathrm{C}$. The degradation temperature was similar to that of MOF-5, which meant that the affinity thiophilic material has good thermal stability.

The modest surface area for separated sorbent in chromatography was $200-800 \mathrm{~m}^{2} \mathrm{~g}^{-1}$ and the pore size in the range of 2-25 nm [32]. From the $\mathrm{N}_{2}$ adsorption-desorption isotherm in Fig. 8, the average pore size

\section{SN Applied Sciences}




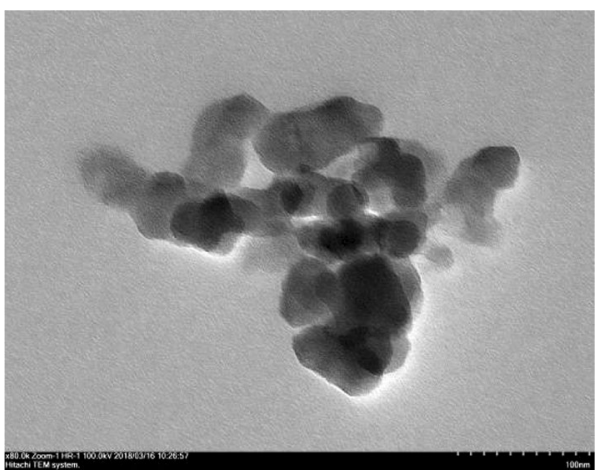

Fig. 4 TEM images of MOF-5-NH $\mathrm{N}_{2} @ P(T E P I C-C O-S F A)$

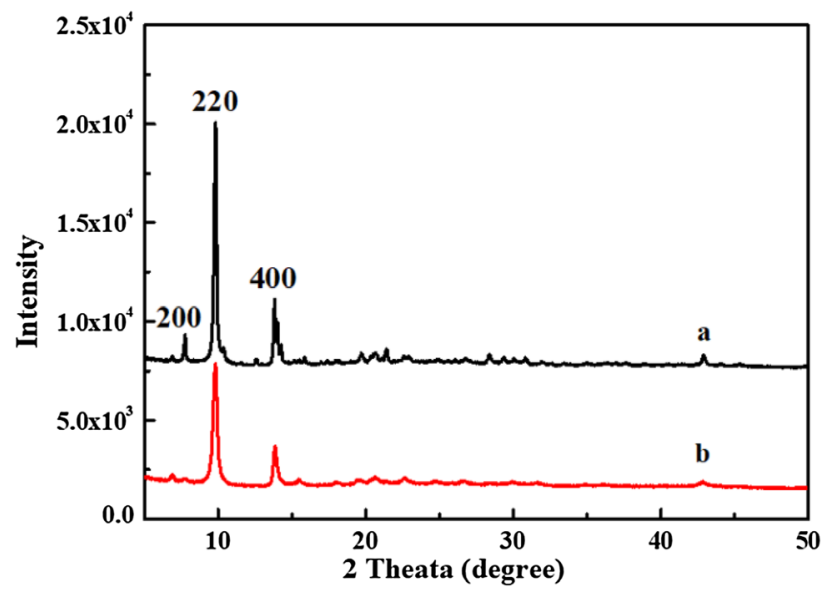

Fig. 5 XRD pattern of (a) MOF-5- $\mathrm{NH}_{2}$, (b) MOF-5-NH $\mathrm{N}_{2} @ P(T E P I C-C O-$ SFA)

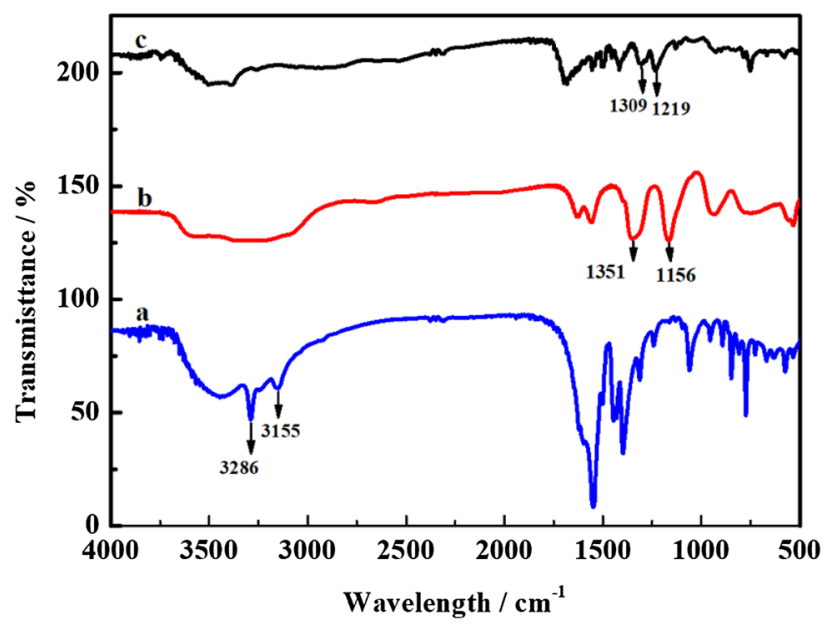

Fig. 6 FT-IR spectra of (a) MOF-5-NH ${ }_{2}$ (b) SFA, (c) MOF-5$\mathrm{NH}_{2} @ P(T E P I C-C O-S F A)$

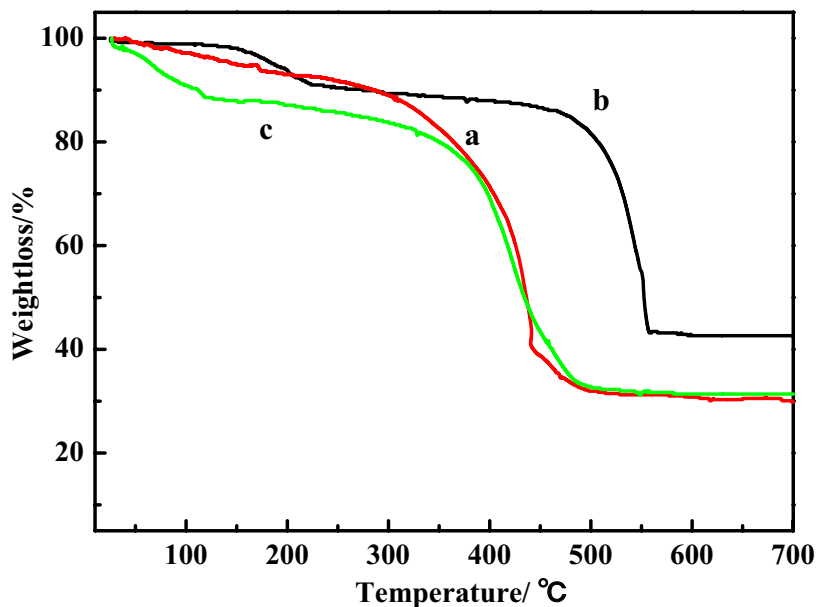

Fig. 7 TGA curve of (a) MOF-5, (b) MOF-5-NH ${ }_{2}$ (c) MOF-5$\mathrm{NH}_{2} @ P(T E P I C-C O-S F A)$

of MOF-5-NH $\mathrm{N}_{2} @$ P(TEPIC-CO-SFA) was $15.58 \mathrm{~nm}$ and the surface area $248.14 \mathrm{~m}^{2} \mathrm{~g}^{-1}$ As for MOF-5- $\mathrm{NH}_{2}$, the data is $15.83 \mathrm{~nm}$ and $81.77 \mathrm{~m}^{2} \mathrm{~g}^{-1}$. The pore size is retained after hybridation, however, the surface area was increased threefold, which make the obtained sample has a suitable surface condition for sorbent. In addition, as a functional monomer, SFA provide hydrophilic group, including sulfonyl group $(\mathrm{O}=\mathrm{S}=\mathrm{O})$ and amino group $\left(-\mathrm{NH}_{2}\right)$, which made the sorbent possessed hydrophilicity. The prepared polymer-MOF hybrid material was more suitable for liquid separation.

\subsection{Thiophilic affinity}

\subsubsection{Experimental conditions of capillary electrophoresis}

All capillary electrophoresis data were obtained from capillary electrophoresis apparatus. A new fused silica capillary column with total length up to $50 \mathrm{~cm}$ was put into use. The detection wavelength was set at $214 \mathrm{~nm}$. The separated voltage was $15 \mathrm{kV}$. Before each injection, the column was rinsed by $0.1 \mathrm{~mol} \mathrm{~L}^{-1} \mathrm{NaOH}, 0.1 \mathrm{~mol} \mathrm{~L}^{-1} \mathrm{HCl}$, ultrapure $\mathrm{H}_{2} \mathrm{O}$ and $0.05 \mathrm{~mol} \mathrm{~L}^{-1}$ background buffer solution in sequence under the pressure of $20 \mathrm{psi}$. The condition of sample injection was $0.5 \mathrm{psi} \times 8 \mathrm{~s}$.

\subsubsection{Adsorption of compounds containing disulfide-bond}

The whole procedure for specific enrichment and separation of compounds containing disulfide-bond includes three steps: immobilized, washing, and elution (Fig. 9). Firstly, $10 \mathrm{mg}$ thiophilic affinity absorbent was put into a $1.5 \mathrm{~mL}$ centrifuge tube, and $600 \mu \mathrm{L}$ loading buffer and $800 \mu \mathrm{L}$ mixed standard solution were added. In order to 
immobilize the disulfide bond-containing compound on the sorbent, the mixture was sufficient vibrated for $20 \mathrm{~min}$, and then the supernatant liquid was discarded after centrifugation. Subsequently, $300 \mu \mathrm{L}$ loading buffer was added and repeated the operation of sufficient fixation for twice. Finally, the supernatant liquid was collected for capillary electrophoresis analysis after $15 \mu \mathrm{L}$ eluent was added and vibrated for $10 \mathrm{~min}$.

On the basis of the separation mechanism of thiophilic affinity chromatography, we demonstrate the feasibility of the affinity sorbent for specific capture of compound containing disulfide-bond, with bis(4-hydroxyphenyl) disulfide and 4, 4'-Dihydroxydiphenyl methane as the test compounds (Fig. 10). The difference between bis(4-hydroxyphenyl) disulfide and 4,4'-dihydroxydiphenyl methane was that one has disulfide bond and the other has no disulfide bond. From Fig. 11, it can be seen that the captured bis(4-hydroxyphenyl) disulfide has a sharper peak, its peak area was 20 times than that of initial standard sample. It meant that the bis(4-hydroxyphenyl) disulfide was enriched. As a contrast, 4, 4'-Dihydroxydiphenyl methane, which has no disulfide bond, didn't display any $C E$ signal under the same detection condition. The results demonstrated MOF-5-NH $\mathrm{N}_{2} @ \mathrm{P}(\mathrm{TEPIC}-\mathrm{CO}-\mathrm{SFA})$ had apparent affinity to disulfide bond-containing compound.

Additionally, the affinity separation capacity of MOF5- $\mathrm{NH}_{2} @ \mathrm{P}(\mathrm{TEPIC}-\mathrm{CO}-\mathrm{SFA})$ was further investigated with the solution of $2 \mathrm{~S}-\mathrm{OH}\left(0.1 \mathrm{mg} \mathrm{mL}^{-1}\right)$ through the whole
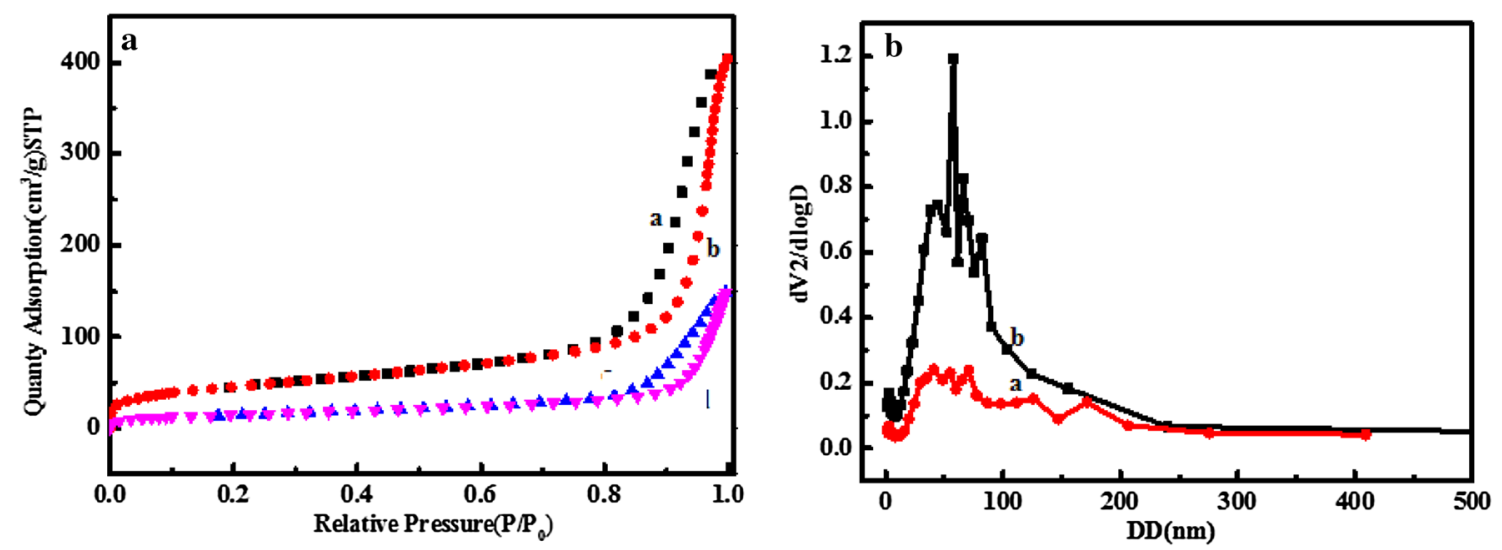

Fig. 8 A N $\mathrm{N}_{2}$ adsorption/desorption isotherm and B pore -size distribution of (a) MOF-5-NH $2^{\prime}$ (b) MOF-5-NH ${ }_{2} @ P(T E P I C-C O-S F A)$

Fig. 9 The proposed mechanism between MOF5- $\mathrm{NH}_{2} @ P($ TEPIC-CO-SFA) and disulfide bond-containing compound
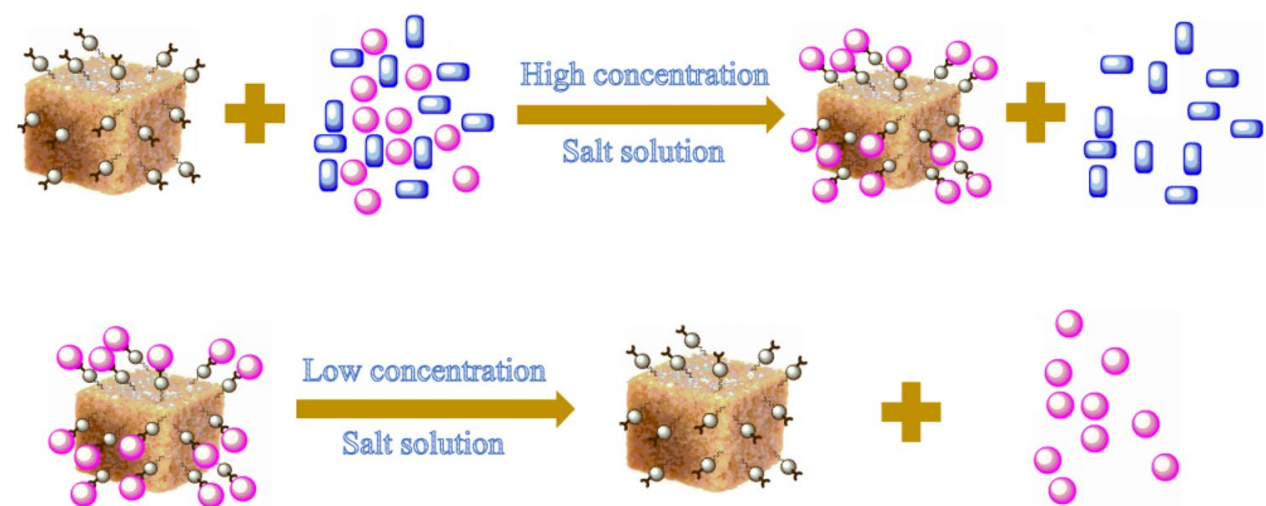

Low concentration
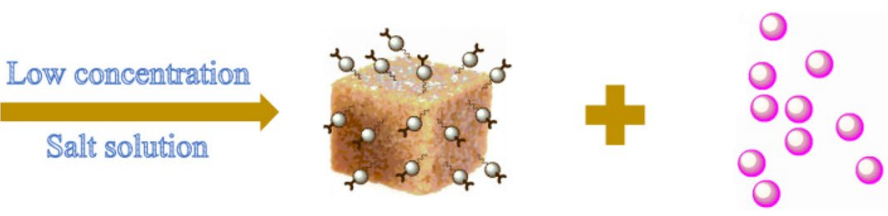

MOF-5-NH $\mathrm{N}_{2} @ \mathrm{P}(\mathrm{TEPIC}-\mathrm{co}-\mathrm{SFA})$

Disulfide bond-contianing compound

0 Non-disulfide bond-contianing compound

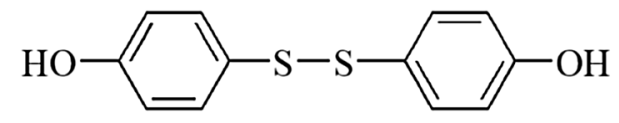

$\mathbf{a}$<smiles>Oc1ccc(Cc2ccc(O)cc2)cc1</smiles>

b

SN Applied Sciences 


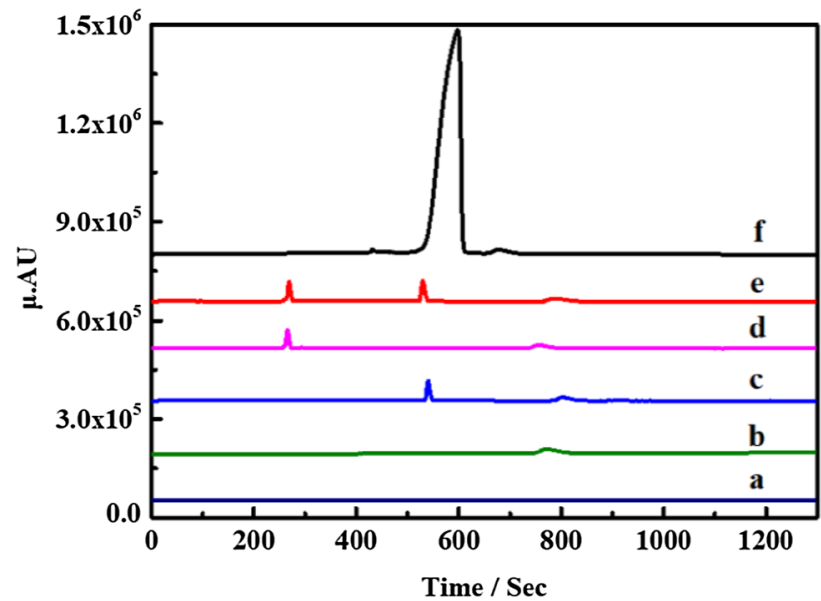

Fig. 11 Electrophoretograms of samples: (a) PBS, (b) eluent, (c) $2 \mathrm{~S}-\mathrm{OH}$ standard solution, (d) 2-OH standard solution, (e) $2 \mathrm{~S}-\mathrm{OH}$ and 2-OH standard mixed solution ( $\mathrm{f}$ ) enriched components

separation process, including the sample loading, washing and elution operations. The relative standard deviation of CE signal for run to run was about $41.92 \%$, and batch to batch was about $28.07 \%$.

\section{Conclusions}

In this paper, a method for preparation of thiophilic affinity sorbent was proposed through combing the MOF with polymer. The designed and synthesized sorbent can specifically capture disulfide bond-containing compounds. Especially, the hydrophilic functional monomer facilitates its application in the water system. Because of the widespread presence of compounds containing disulfide-bond in nature, such as, proteins, antibody. The application of MOFs will be well designed and functionalized to make the thiophilic affinity sorbents a promising material in the near future.

Acknowledgements We gratefully acknowledge the "National Natural Science Foundation of China" (Grant No. 21405003), and Open fund of "Beijing Key Laboratory of Detection Technology and Quality Evaluation of Organic Material" (Grant No. 201501003) for financial support.

\section{Compliance with ethical standards}

Conflict of interest The authors declare that they have no conflict of interest.

\section{References}

1. Eddaoudi M, Li H, Yaghi OM (2000) Highly porous and stable metal-organic frameworks: structure design and sorption properties. J Am Chem Soc 122:1391-1397
2. Zhu YL, Zhou XH, Li L, You YJ, Huang W (2017) A water-stable metal-organic framework as a luminescent $\mathrm{Fe}^{3+}$ sensor under weak acidic and weak basic conditions. Sci China Chem 60:1581-1587

3. Gao J, Huang CH, Lin YF, Tong P, Zhang L (2019) In situ solvothermal synthesis of metal-organic framework coated fiber for highly sensitive solid-phase microextraction of polycyclic aromatic hydrocarbons. Chem Eng J 365:40-50

4. Ranjbar M, Taher MA (2016) Preparation of Ni-metal organic framework-74 nanospheres by hydrothermal method for $\mathrm{SO}_{2}$ gas adsorption. J Porous Mater 23:1249-1254

5. Liu YL, Gao PF, Huang CZ, Li YF (2015) Shape- and size-dependent catalysis activities of iron-terephthalic acid metal-organic frameworks. Sci China Chem 58:1553-1560

6. Zeng PY, Li JW, Ye M, Zhuo KF, Fang Z (2017) In situ formation of Co9S8/N-C hollow nanospheres by pyrolysis and sulfurization of ZIF- 67 for high-performance lithium-ion batteries. Chem Eur J 40:9517-9524

7. Zhao YY, Wang WW, Chen MN, Wang RJ, Fang Z (2017) The synthesis of ZnS@MoS2 hollow polyhedrons for enhanced lithium storage performance. CrystEngComm 20:7266-7274

8. Priscilla RB, Idaira PF, Jorge P, Pino V (2016) Are metal-organic frameworks able to provide a new generation of solid-phase microextraction coatings? A review. Anal Chim Acta 939:26-41

9. Yusuf K, Aqel A, ALOthman Z (2014) Metal-organic frameworks in chromatography. J Chromatogr A 1348:1-16

10. Li PZ, Su J, Liu J, Liang J, Zhang YY, Chen HZ, Zhao YL (2017) A highly porous metal-organic framework for large molecule capture and chromatographic separation. Chem Commun 53:3434-3437

11. Huang K (2015) A ZIF-71 hollow fiber membrane fabricated by contra-diffusion. ACS Appl Mater Interfaces 7:16157-16160

12. Bentz KC, Cohen SM (2018) Supramolecular metallopolymers: from linear materials to infinite networks. Angew Chem Int Ed 57:14992-15001

13. Ayala S, Bentz KC, Cohen SM (2019) Block co-polyMOFs: morphology control of polymer-MOF hybrid materials. Chem Sci 10:1746-1753

14. Palomba JM, Credille CV, Kalaj M, DeCoste JB, Peterson GW, Tovar TM, Cohen SM (2018) High-throughput screening of solid-state catalysts for nerve agent degradation. Chem Commun 54:5768-5771

15. Denny MS, Moreton JC, Benz L, Cohen SM (2016) Metalorganic frameworks for membrane-based separations. Nat Rev Mater 1:1-17

16. Zhang YY, Feng X, Li HW, Chen YF, Zhao JS, Wang L, Wang S, Wang B (2015) Photoinduced postsynthetic polymerization of a metal-organic framework toward a flexible stand-alone membrane. Angew Chem Int Ed 54:4259-4263

17. Marti A, Tran D, Balkus KJ (2015) Fabrication of a substituted imidazolate material 1 (SIM-1) membrane using post synthetic modification (PSM) for pervaporation of water/ethanol mixtures. J Porous Mater 22:1275-1284

18. Yao BJ, Jiang WL, Dong Y, Liu ZX, Dong YB (2016) Post-synthetic polymerization of UiO-66- $\mathrm{NH}_{2}$ nanoparticles and polyurethane oligomer toward stand-alone membranes for dye removal and separation. Chem Eur J 22:10565-10571

19. Qian H, Lin ZY, Xu HM, Chen MQ (2009) The efficient and specific isolation of the antibodies from human serum by thiophilic paramagnetic polymer nanospheres. Biotechnol Progr 25:376-383

20. Porath J, Maisano F, Belew M (1985) Thiophilic adsorption-a new method for protein fractionation. FEBS Lett 185:306-310

21. Srikrishnan T, MacKenzie JT, Sulkowski E (2006) Thiophilic interaction chromatography of human transferrins. J Chromatogr Sci 44:634-638 
22. Kawinski E, Levine E, Chadha K (2002) Thiophilic interaction chromatography facilitates detection of various molecular complexes of prostate-specific antigen in biological fluids. Prostate 50:145-153

23. Salgado FJ, Vazquez $S$, Iglesias $A$, Perez DA, Mera VA, Arias $P$, Nogueira M (2010) Application of thiophilic chromatography to deplete serum immunoglobulins in sample preparation for bidimensional electrophoresis. Anal Chim Acta 658:18-31

24. Zhang SH, Yang Q, Yang XM, Wang WC, Li Z, Zhang LH, Wang C, Wang Z (2017) A zeolitic imidazolate framework based nanoporous carbon as a novel fiber coating for solid-phase microextraction of pyrethroid pesticides. Talanta 166:46-53

25. Cendrowski K, Skumial P, Spera P, Mijowska E (2016) Thermally induced formation of zinc oxide nanostructures with tailoring morphology during metal organic framework (MOF-5) carbonization process. Mater Des 110:740-748

26. Greer HF, Liu YH, Greenaway A, Wright PA, Zhou WZ (2016) Synthesis and formation mechanism of textured MOF-5. Cryst Growth Des 16:2104-2111

27. Chen B, Wang XJ, Zhang QF, Xi XY, Cai JJ, Qi H, Shi S, Wang J, Yuan D, Fang M (2010) Synthesis and characterization of the interpenetrated MOF-5.J Mater Chem 20:3758-3767

28. Kaye SS, Dailly A, Yaghi OM, Long JR (2007) Impact of preparation and pandling on the hydrogen storage properties of
$\mathrm{Zn}_{4} \mathrm{O}\left(1,4-\right.$ benzenedicarboxylate) ${ }_{3}(\mathrm{MOF}-5)$. J Am Chem Soc 129:14176-14177

29. Yaghi OM, Keeffe MO, Ockwig NW, Chae HK, Eddaoudi M, Kim $J$ (2003) Reticular synthesis and the design of new materials. Nature 423:705-714

30. Zhu LJ, Jia XY, Bian H, Huo T, Duan ZB, Xiang YZ, Xia DH (2018) Structure and adsorptive desulfurization performance of the composite material MOF-5@AC. New J Chem 42:3840-3850

31. Liu YC, Ren LB, Liu Z (2011) A unique boronic acid functionalized monolithic capillary for specific capture, capture, separation and immobilization of cis-diol biomolecules. Chem Commun 47:5067-5069

32. Ahmad R, Wongfoy AG, Matzger AJ (2009) Microporous coodination polymers as selective sorbents for liquid chromatography. Langmuir 25:11977-11979

Publisher's Note Springer Nature remains neutral with regard to jurisdictional claims in published maps and institutional affiliations. 